\title{
Neonatal Sepsis: Clinical Considerations
}

\author{
S. Blatt ${ }^{1}$ M. Schroth ${ }^{1}$ \\ ${ }^{1}$ Neonatologie und Pädiatrische Intensivmedizin, Cnopf'sche \\ Kinderklinik, Nürnberg, Germany \\ J Child Sci 2017;7:e54-e59.
}

\begin{abstract}
Address for correspondence S. Blatt, MD, Neonatologie und Pädiatrische Intensivmedizin, Cnopf'sche Kinderklinik, St.-JohannisMühlgasse 19, 90419 Nürnberg, Germany

(e-mail: sophie.blatt@diakonieneuendettelsau.de).
\end{abstract}

\begin{abstract}
Keywords

- neonatal sepsis

- late-onset

- early-onset

- group B Streptococcus

- diagnosis

Unspecific symptoms and rapid development of sepsis up to septic shock from systemic inflammatory response syndrome (SIRS) are well-known, important issues in neonatology. A common cause is the infection by Streptococcus agalactiae (Group B Streptococcus [GBS]) or Escherichia coli, which contributes significantly to neonatal morbidity and mortality. Whereas early-onset sepsis is normally derived from mother during birth, late-onset sepsis can be transmitted by the environment. Management of neonatal sepsis includes the maintenance of cardiovascular and pulmonary function besides antibiotic therapy. Due to the fact that until today, there are no reliable screening tests for detecting early sepsis, clinical assessment is considered to be of utmost importance.
\end{abstract}

\section{Introduction}

Sepsis is a severe clinical feature in neonates, especially in very-low-birth weight (VLBW) infants. ${ }^{1}$ In 2005 , the International Consensus Conference of Pediatric Sepsis (CCPS) published new definitions of systemic inflammatory response syndrome (SIRS), sepsis, severe sepsis, and septic shock (-Tables 1 and 2). ${ }^{2}$

SIRS is described as a nonspecific inflammatory process, which can also occur after surgical interventions, birth trauma, or vaccinations, whereas sepsis includes a proven infection by positive blood culture or at least a severe suspected infection. Developing organ dysfunction leads to the diagnosis of severe sepsis and finally septic shock. ${ }^{2-4}$ In addition to the definition by CCPS, the criteria of the leading neonatological infection board in Germany "NEO-KISS" (Neo = Neonatology, KISS = Krankenhaus-Infektions-Surveillance-System) include hyperglycemia, metabolic acidosis, prolonged capillary refilling time, as well as other clinical signs of sepsis. However, it must be pointed out that "NEO-KISS" includes only preterm infants weighing less than $1,500 \mathrm{~g} .{ }^{5}$ Although there are clearly defined parameters, the transition between SIRS to sepsis and finally septic shock is fluid.

received

December 14, 2016 accepted after revision December 20, 2016
Issue Theme Pediatric Sepsis Biomarkers; Guest Editors: Peter Dahlem, MD, PhD, Marijan Saraga, MD, PhD, Walter L. Strohmaier, MD, PhD

DOI https://doi.org/ 10.1055/s-0037-1603802. ISSN 2474-5871.
In contrast, Singer et al published updated definitions of sepsis and septic shock-based on the knowledge in intensive care medicine for adults. Sepsis is defined as a life-threatening organ dysfunction caused by a dysregulated host response to infection. A Sequential Organ Failure Assessment (SOFA) score greater than 2 should be used to recognize patients at risk. Septic shock includes severe cellular, circulatory, and metabolic abnormalities such as the need for catecholamines and high lactate level. The term, "severe sepsis," is not useful anymore. Using the new quickSOFA score, including respiratory rate, altered mentation, and low systolic blood pressure, patients at risk for poor outcome can be identified easily (-Table 3). Unfortunately, these new definitions are not particularly for preterm infants or neonates. ${ }^{6}$

Regarding the clinical risk factors and different specimens, it is reasonable to classify the infections according to their onset. Referring to guidelines of "Deutsche Gesellschaft für Pädiatrische Infektiologie" (DGPI), early-onset sepsis (EOS) implicates a critical illness within 3 days after birth. ${ }^{7}$ In the American literature, EOS is variably defined based on the age. According to the special setting, in VLBW infants $(<1,500 \mathrm{~g})$, the definition of early-onset sepsis is also restricted to infections within the first 72 hours. Although in

Copyright ( 2017 Georg Thieme Verlag License terms KG Stuttgart · New York

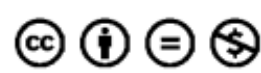


Table 1 Sepsis criteria

\begin{tabular}{|l|l|}
\hline \multicolumn{2}{|l|}{ SIRS } \\
\hline & $\begin{array}{l}\text { The presence of at least two of the following four criteria, one of which must be abnormal temperature or leukocyte } \\
\text { count: } \\
\text { Core temperature of }>38.5 \text { or }<36{ }^{\circ} \mathrm{C} \\
\text { Tachycardia or bradycardia } \\
\text { Tachypnea or mechanical ventilation } \\
\text { Leukocyte count elevated or depressed for age }\end{array}$ \\
\hline \multicolumn{1}{|c|}{ Sepsis } \\
\hline \multicolumn{1}{|l|}{ SIRS in the presence of or as a result of suspected or proven infection } \\
\hline \multicolumn{2}{|l|}{ Severe sepsis } \\
\hline Septic shock & Sepsis and cardiovascular organ dysfunction \\
\hline
\end{tabular}

Abbreviation: SIRS, systemic inflammatory response syndrome.

Source: Adapted from Goldstein et al. ${ }^{2}$

Table 2 Age specific vital signs

\begin{tabular}{|l|l|l|l|l|}
\hline Age & \multicolumn{2}{|l|}{$\begin{array}{l}\text { Heart rate } \\
\text { (beats/min) }\end{array}$} & Respiratory rate (breath/min) & Leucocyte count $(1,000 / \mu \mathrm{L})$ \\
\hline $0 \mathrm{~d}$ to $1 \mathrm{wk}$ & $>180$ & $<100$ & $>50$ & $>34$ \\
\hline $1 \mathrm{wk}$ to $1 \mathrm{mo}$ & $>180$ & $<100$ & $>40$ & $>19.5$ or $<5$ \\
\hline
\end{tabular}

Source: Adapted from Goldstein et al. ${ }^{2}$

term infants the period of EOS spreads until day $6,8,9$ infections occurring after this period are rather considered to be nosocomial. ${ }^{9}$ Late-onset sepsis appears from day 3 onwards in preterm infants, respectively from day 6 until day 90 after birth in term infants. ${ }^{7,10}$ Furthermore, the differentiation between community-acquired and hospital-acquired infections is of great importance. Unfortunately, there are no consistent definitions of sepsis worldwide.

\section{Early-Onset Sepsis}

Generally, EOS is considered to be derived from the mother during birth. Therefore, typical risk factors are low gestational age (GA; $\leq 32$ weeks of pregnancy; weight $\leq 1,500 \mathrm{~g}$ ), chorioamnionitis, rupture of the membranes (ROMs) more than 18 hours before being in labor and group B streptococcal (GBS) colonization. ${ }^{7}$

Preterm infants are especially at a high risk of EOS. The ratio of infection rises inversely proportional to the GA. Hence, the majority of prematurity is caused by chorioamnionitis. ${ }^{7}$ Notably, early-onset sepsis has a stronger associa-

Table 3 QuickSOFA Criteria

\begin{tabular}{|l|l|}
\hline Respiratory rate & $>22 / \mathrm{min}$ \\
\hline Altered mentation & \\
\hline Systolic blood pressure & $\geq 100 \mathrm{~mm} \mathrm{Hg}$ \\
\hline
\end{tabular}

Abbreviation: SOFA, Sequential Organ Failure Assessment. Source: Adapted from Singer. ${ }^{6}$ tion with low GA than with low birth weight. ${ }^{9,11}$ Even for moderate preterm infants, a higher risk is described. ${ }^{12}$ Immunoglobulin $\mathrm{G}(\mathrm{IgG})$ is transferred from mother to fetus only in the third trimester of pregnancy; therefore, preterm infants have a decreased base line serum IgG concentration and are mostly dependent on their innate immune system. ${ }^{13}$

Maternal fever, fetal tachycardia, uterine tenderness, or foul odors of the amniotic fluid, as well as elevated maternal infectious parameters (temperature $>38^{\circ} \mathrm{C}$, C-reactive protein [CRP] $>20 \mathrm{mg} / \mathrm{L}$, and leukocytosis) evoke the clinical diagnosis of chorioamnionitis-a known risk factor for EOS. The level of maternal fever correlates with the risk of neonatal infection. ${ }^{7,9}$

Generally, fetal membranes act as a barrier to protect the fetus from infections. ROMs before being in labor (premature) or before 37 weeks of GA (preterm) is an important risk factor. ROM prior than 18 hours before delivery is associated with an increased risk of infection with GBS. ${ }^{8,9}$

A well-known and common cause of EOS is infection caused by GBS. Fluegge et al showed in 2006 that approximately $60 \%$ of GBS infections are early-onset diseases. ${ }^{14}$ Since the start of antibiotic prophylaxis, the rate of GBS infections reduced significantly. ${ }^{15}$ Usually, the infection is due to colonized amniotic liquor. According to current German guidelines, a maternal screening using an anorectal and vaginal swap is recommended. In case of colonization, an intrapartum antibiotic prophylaxis (IAP) during labor should be performed. Furthermore, IAP is offered to all pregnant women with preterm labor, premature ROMs $>18 \mathrm{~h}$, or fever 
$>38^{\circ} \mathrm{C}$ in labor. In case of primary caesarian section without ROMs before labor, prophylaxis is not necessary. Fifty percent of the colonized women transfer GBS to the newborn, of which, again approximately 1 to $2 \%$ develop sepsis. ${ }^{13-15}$

It is obvious that every newborn with symptoms of infection needs antibiotic therapy. Thus, it is not well known how asymptomatic infants should be treated in case of maternal risk factors. Frequent clinical reevaluation for at least 48 hours and the measurement of infectious blood parameters are essential. ${ }^{15}$

\section{Late-Onset Sepsis}

Late-onset infection can be transmitted vertically as well as horizontally. It is also indicated to differentiate between nosocomial and environmental sources. ${ }^{14}$

The rate of LOS is similar to EOS, and inversely proportional to GA and birth weight. In particular, VLBW infants are at an increased risk. In addition, male gender and decreased base line IgG concentration contribute to increased morbidity. ${ }^{11}$ According to Giuffrè et al, low GA, birth weight, mechanical ventilation, use of antibiotics, or invasive devices are no longer considered as independent risk factors. ${ }^{16}$ Nevertheless, the most important risk factor for the horizontal acquisition of nosocomial infections is the infant's caregiver. ${ }^{7}$

About two-thirds of patients with nosocomial infection are infants weighing less than $1,500 \mathrm{~g}$ birth weight. ${ }^{17}$ In some cases, patients at the neonatal intensive care unit (NICU) are colonized with microorganisms and lack any clinical symptoms. In particular, cross-dissemination of multidrug resistant gram-negative bacteria (MDRGN) may occur by the touch of parents and caregiver, daily care including changing napkins as well as through contaminated equipment. Exclusive feeding with formula is a significant pathway for cross-transmission due to contamination during manufacture or preparation by the healthcare staff. Breastfeeding, on the other hand, seems extended to protect from spectrum beta-lactamase (ESBL) colonization. ${ }^{18}$ The time of hospitalization at the NICU is an additional risk factor. ${ }^{16}$

Therefore, preterm infants are at a high risk of nosocomial infections. For this reason, in 1994, a pilot project for a surveillance system of nosocomial infections in German neonatal intensive care units was initiated. ${ }^{17}$ Since then, "NEO-KISS" is an established system to evaluate methods to prevent infections.

\section{Microbiological Considerations}

Depending on GA, different bacteria might potentially cause sepsis. In EOS, normally the flora of the maternal birth canal is the causative agent. Second to none, E. coli is the most proven infectious agent, followed by GBS, and more rarely, Staphylococcus aureus or Listeria.

For preterm infants born after 2 days of maternal antibiotic treatment, infection caused by Klebsiella, Pseudomonas, or ampicillin-resistant E. coli is expected. ${ }^{7,9}$ Coagulase negative Staphylococcus (e.g., S. epidermidis, S. haemolyticus, S. aureus) is a typical microbe causing nosocomial infections; this infection occurs at the earliest after the third day of hospitalization. ${ }^{7}$ Mycosis is extremely rare and affects rather extreme preterm infants of 24th to 25th week of pregnancy. ${ }^{7}$ It is well known that term infants present higher rates of GBS infection, whereas preterm infants and newborn with lower birth weight are more often infected with E. coli. ${ }^{19}$

\section{Diagnosis}

The early diagnosis of sepsis is difficult due to unspecific clinical signs in neonates, especially in VLBW infants. Until today, many physicians trust biochemical markers regardless of a lack of specificity and poor diagnostic accuracy of these biomarkers in the first hours of infection. Therefore, the early diagnosis of sepsis should mainly rely on clinical signs. ${ }^{3}$

\section{Clinical Signs}

Despite a wide range of publications concerning the diagnosis of bacterial infections, there are no reliable screening tests for sepsis. It is necessary to reevaluate the clinical as well as laboratory findings several times to evaluate the progress of infection.

For preterm infants, clinical suspicion of SIRS or sepsis is based on inconspicuous clinical findings. Typically, the caregivers point to the discrete change in clinical state and to the "not right acting" infant. ${ }^{4} \mathrm{An}$ increase in apneic episodes or the need of positive pressure ventilation as well as an increased ventilator support or fraction of inspired oxygen $\left(\mathrm{F}_{\mathrm{i}} \mathrm{O}_{2}\right)>25 \%$, temperature instability $\left(>38\right.$ or $<36.2^{\circ} \mathrm{C}$ ), arterial hypotonia, feeding intolerance, or lethargy should direct the clinician's attention to neonatal sepsis. ${ }^{4}$

The American College of Critical Care Medicine (ACCCM) suggests the clinical diagnosis of sepsis in any newborn with tachycardia, respiratory distress or tachypnea, poor feeding, poor muscle tone, poor color, reduced perfusion or diarrhea, especially, if there are any risk factors such as chorioamnionitis or history of premature ROMs. ${ }^{2,3}$

Similar symptoms can also be caused by congenital heart disease or metabolic disorders; therefore, these conditions should be ruled out. ${ }^{3}$

Any clinically reasonable suspicion is enough to indicate an immediate therapy. Before starting treatment, a blood culture should be taken-although just in approximately 10 to $20 \%$, a positive result follows. ${ }^{20}$ Nevertheless, a positive blood culture should influence the duration of antibiotic therapy. Even with a blood sample less than $0.5 \mathrm{~mL}$, the rate of false negative results is less than expected, a fact that can be explained by higher concentration of the microorganisms ( $>5$ colony forming units $[\mathrm{CFUs}] / \mathrm{mL}$ ) in neonates..$^{20}$

\section{Cardiac Considerations}

Decreased variability and transient decelerations of heart rate are common parameters to detect fetal distress using a cardiotocograph. However, even after birth, these abnormal heart rate characteristics are shown to be associated with a beginning sepsis. Impressively, these changes can be detected in preterm infants often before clinical signs appear. ${ }^{21}$ Heart rate findings can be used to direct the attention to very subtle clinical signs of illness and lead to an earlier evaluation and therapy of the patient. In combination with 
blood tests such as measuring CRP or white blood cell (WBC) count, analysis of the patient's heart rate might provide a chance to improve diagnostic accuracy. Nevertheless, clinical judgment and experience are still necessary for the proper assessment, because other infection-related conditions such as necrotizing enterocolitis as well as acute deterioration in respiratory status or surgery could lead to similar clinical features. .,21,22 $^{-2}$

\section{Laboratory Considerations}

Laboratory findings include an abnormal WBC count $(>25,000 / \mu \mathrm{L}$ or $<5,000 / \mu \mathrm{L})$ as well as an immature/total neutrophil ratio $(\mathrm{I}: \mathrm{T})>0.2$. However, hyperglycemia is also a risk factor for neonatal sepsis. ${ }^{4}$

Resch et al suggested the I/T ratio to be an important and early parameter for the diagnosis of EOS. ${ }^{19}$ Unfortunately, interpretation of the $\mathrm{I} / \mathrm{T}$ ratio is dependent on the experience of the laboratory staff to differentiate granulocytes using morphological criteria.

\section{Management and Therapy}

\section{Fluid Therapy}

For the management of septic shock, it is most important to establish a peripheral or intraosseous access as fast as possible. ACCM recommends a bolus of at least $20 \mathrm{~mL} / \mathrm{kg}$ for initiating fluid resuscitation. ${ }^{23}$ If there are still signs of shock such as tachycardia, respiratory distress, and poor color in neonates, another two boluses of $20 \mathrm{~mL} / \mathrm{kg}$ (a total of $60 \mathrm{~mL} / \mathrm{kg}$ ) are indicated. ${ }^{3}$ Actually, balanced crystalloid solutions are recommended not only in adults but also in pediatric intensive care. ${ }^{24-27}$ The use of crystalloid fluids in neonatology, especially in preterm infants, has to be investigated.

In consideration of signs of heart failure such as an enlarged liver or rales on lung examination, fluid therapy should immediately be stopped. ${ }^{3,23,28}$ Even in current reviews, the recommendation has not changed. It should be kept in mind that a fluid overload can also be dangerous and an early use of catecholamines should be considered. ${ }^{29}$

\section{Cardiovascular Support}

The majority of neonates suffering from severe shock need cardiovascular assistance. To obtain a significant cardiac output, inotrope drugs are recommended. A first line treatment consists of catecholamines such as dobutamine, epinephrine, or norepinephrine. ${ }^{23}$ Norepinephrine should be used in warm shock with unaffected microcirculation and lack of myocardial dysfunction. Regarding the vasoconstrictor side effect of norepinephrine, the combination with dopamine or dobutamine must be considered. In case of decompensation with prolonged capillary refilling time and heart dysfunction, epinephrine is recommended. ${ }^{23}$ If low cardiac output and signs of high vascular resistance after high-dose application of epinephrine persist, the use of phosphodiesterase inhibitors for neonates is recommended. ${ }^{3}$

\section{Airway Management}

Patients with acute sepsis are at a risk to develop pulmonary dysfunction. Therefore, application of oxygen is an essential part of acute sepsis management. In case of acute respiratory deterioration, artificial ventilation should be performed early. ${ }^{24}$ Brower et al showed that the use of higher versus lower positive end-expiratory pressure does not influence the clinical outcome significantly. ${ }^{30}$

A very specific finding in newborn septic shock is the persistence of fetal circulation (PFC) due to increased pulmonary vascular resistance leading to right-to-left shunting. Therefore, nitric oxide should be applied, if necessary. ${ }^{3}$

\section{Antibiotics}

Both in SIRS and sepsis, the use of intravenous antibiotics is crucial. However, there is no unique antibiotic treatment strategy in preterm infants or neonates. ${ }^{10}$ According to German guidelines, every SIRS infection should be treated for at least 7 days, whereas patients with sepsis proven by positive blood culture should receive antibiotic therapy for up to 10 days. Meningitis treatment is recommended for a period of 2 to 3 weeks. $^{7}$

\section{Immunomodulatory Therapy}

The IgG antibodies are transferred from mother to fetus only in the third trimester of pregnancy. Therefore, preterm infants lack maternal specific antibodies. Furthermore, the sufficient endogenous immunoglobulin production starts several months after birth. Therefore, neonates are mostly dependent on their innate immune system. ${ }^{13}$ By taking blood samples and performing erythrocyte transfusions, the deficiency is aggravated. ${ }^{31}$ Nevertheless, Ohlsson et al do not suggest an advantage after administration of intravenous immunoglobulins. ${ }^{32}$

\section{Prevention}

The very early and straightly aggressive management is a feasible way for the reduction of mortality and morbidity in acute neonatal sepsis. ${ }^{23}$ Prevention of this high-risk illness should be the most important issue and the aim of any treatment strategy. The nursing staff, dealing with these patients every day, has to be well educated. Furthermore, it is important to provide an adequate number of caregivers depending on the number of preterm infants. ${ }^{28}$ At the moment, the impact of nurse-to-patient ratio on the outcome is not well investigated. Naturally, a high workload as well as a low nurse-to-patient ratio is a risk factor for mortality in adult intensive care units. According to Sherenian et al, there are no data for NICUs. ${ }^{33}$

From January 2017, a new legislation concerning the care of term and preterm infants started in Germany. The aim is to especially provide a one-to-one nurse-to-patient ratio for preterm infants weighing less than 1,500 g. Nevertheless, it will need time until the realization is completed and the new data are generated. ${ }^{34}$

Surveillance is a proven method to reduce nosocomial infections. According to the American National Nosocomial 
Infections Surveillance (NNIS) system, an independent German surveillance system for NICUs, "NEO-KISS," is well established for all the level 3 NICUs in Germany since $1994 .{ }^{17}$

\section{Outcome}

Regarding GBS infections in Germany, Fluegge et al showed that invasive infections influence the outcome of neonates significantly. Already, $13 \%$ of patients after GBS infection showed sequelae at the time of discharge-without considering long-term follow-up. ${ }^{14}$ For example, hearing loss at the point of discharge from NICU is approximately 2 to $15 \%$, compared with $0.2-0.3 \%$ in healthy, full-term neonates. This is amongst other factors, such as genetic predisposition or meningitis, attributed to the use of ototoxic aminoglycosides for SIRS and sepsis. Furthermore, endotoxemia and inflammation seem to elevate the uptake of antibiotics in the cochlea. ${ }^{35}$

Moreover, infants with infections as well as clinical sepsis have up to $50 \%$ higher rate of neurodevelopmental impairment (NDI). ${ }^{36}$

In the very early presentation of SIRS and sepsis, there is often barely a noticeable change in the clinical presentation of neonates. Hence, it is the task of the physician in charge to monitor as exactly as possible the vital signs and other clinical criteria to identify the patients at risk. At last, the timely identification of neonates at risk as well as the immediate treatment are aimed to reduce morbidity and mortality and improve the outcome. The implementation of heart rate characteristics seems to be a promising tool. However, only the synopsis of clinical features, predictive monitoring, and an experienced physician would enable a responsible therapy.

\section{References}

1 Müller A, Berner R, Bartmann P. Monatsschr Kinderheilkd 2014; 162:411. Doi:10.1007/s00112-013-2975-7

2 Goldstein B, Miroir B, Randolph A. International Consensus Conference on Pediatric S. International pediatric sepsis consensus conference: definitions for sepsis and organ dysfunction in pediatrics. PediatrCrit Care Med 2005;6(01):2-8

3 Koch L, Bosc A, Sassed M, Ruef P, Poersch J. Managing neonatal severe sepsis in Germany: a preliminary survey of current practices. KilnPediatry 2015;227(01):23-27

4 Griffin MP, Lake DE, O'Shea TM, Moorman JR. Heart rate characteristics and clinical signs in neonatal sepsis. Pediatry Res 2007; 61(02):222-227

5 InfectionNRfSvn. Modul NEO-KISS (Surveillance System nosokomialerInfektionenfürFrühgeborene auf Intensivstationen). Available at http://www.nrz-hygiene.de/surveillance/kiss/neo-kiss/. Accessed December 20, 2016

6 Singer M. The new sepsis consensus definitions (Sepsis-3): the good, the not-so-bad, and the actually-quite-pretty. Intensive Care Med 2016;42(12):2027-2029

7 DGPI DGfPI, Ed. Handbuch, und Jugendlichen. 6. Auflage ed. Stuttgart: Georg Thieme Verlag Kg; 2013

8 Simonsen KA, Anderson-Berry AL, Delair SF, Davies HD. Earlyonset neonatal sepsis. ClinMicrobiol Rev 2014;27(01):21-47

9 Mukhopadhyay S, Puopolo KM. Risk assessment in neonatal early onset sepsis. SeminPerinatol 2012;36(06):408-415

10 Bulkowstein S, Ben-Shimol S, Givon-Lavi N, Melamed R, Shany E, Greenberg D. Comparison of early onset sepsis and community- acquired late onset sepsis in infants less than 3months of age. BMC Pediatr 2016;16:82. Doi: 10.1186/s12887-016-0618-6

11 Fanaroff AA, Korones SB, Wright LL, et al; The National Institute of Child Health and Human Development Neonatal Research Network. Incidence, presenting features, risk factors and significance of late onset septicemia in very low birth weight infants. Pediatr Infect Dis J 1998;17(07):593-598

12 Cohen-Wolkowiez M, Moran C, Benjamin DK, et al. Early and late onset sepsis in late preterm infants. Pediatr Infect Dis J 2009;28 (12):1052-1056

13 Henneke P, Berner R. SIRS and group-B streptococcal sepsis in newborns: pathogenesis and perspectives in adjunctive therapy. Semin Fetal Neonatal Med 2006;11(05):333-342

14 Fluegge K, Siedler A, Heinrich B, et al; German Pediatric Surveillance Unit Study Group. Incidence and clinical presentation of invasive neonatal group B streptococcal infections in Germany. Pediatrics 2006;117(06):e1139-e1145

15 Leitlinie der Gesellschaft für Neonatologie und Pädiatrische Intensivmedizin, Deutsche Gesellschaft für Gynäkologie und Geburtshilfe. Prophylaxe der Neugeborenensepsis - frühe Formdurch Streptokokken der Gruppe B. AWMF-Leitlinien-Register, Nr. 024/020

16 Giuffrè $\mathrm{M}$, Geraci DM, Bonura $\mathrm{C}$, et al. The increasing challenge of multidrug-resistant gram-negative bacilli: results of a 5 -year active surveillance program in a neonatal intensive care unit. Medicine (Baltimore) 2016;95(10):e3016. Doi: 10.1097/MD.0000000000003016

17 Gastmeier P, Geffers C, Schwab F, Fitzner J, Obladen M, Rüden H. Development of a surveillance system for nosocomial infections: the component for neonatal intensive care units in Germany. J Hosp Infect 2004;57(02):126-131

18 Mammina C, Di Carlo P, Cipolla D, et al. Surveillance of multidrugresistant gram-negative bacilli in a neonatal intensive care unit: prominent role of cross transmission. Am J Infect Control 2007; 35(04):222-230

19 Resch B, Renoldner B, Hofer N. Comparison between pathogen associated laboratory and clinical parameters in early-onset sepsis of the newborn. Open Microbiol J 2016;10:133-139

20 Jawaheer G, Neal TJ, Shaw NJ. Blood culture volume and detection of coagulase negative staphylococcal septicaemia in neonates. Arch Dis Child Fetal Neonatal Ed 1997;76(01):F57-F58

21 Lake DE, Fairchild KD, Moorman JR. Complex signals bioinformatics: evaluation of heart rate characteristics monitoring as a novel risk marker for neonatal sepsis. J ClinMonitComput 2014; 28(04):329-339

22 Sullivan BA, Grice SM, Lake DE, Moorman JR, Fairchild KD. Infection and other clinical correlates of abnormal heart rate characteristics in preterm infants. J Pediatr 2014;164(04):775-780

23 Kissoon N, Orr RA, Carcillo JA. Updated American College of Critical Care Medicine-pediatric advanced life support guidelines for management of pediatric and neonatal septic shock: relevance to the emergency care clinician. PediatrEmerg Care 2010;26(11):867-869

24 Seidemann K, Dohna-Schwake C, Keil J, Sasse M. Monatsschr Kinderheilkd 2014;162:156. Doi:10.1007/s00112-013-3071-7

25 Medeiros DN, Ferranti JF, Delgado AF, de Carvalho WB. Colloids for the initial management of severe sepsis and septic shock in pediatric patients: asystematic review. PediatrEmerg Care 2015; 31(11):e11-e16

26 Leitlinie der Deutschen Gesellschaft für Anästhesiologie und Intensivmedizin. Intravasale Volumentherapie beim Erwachsenen. AWMF-Leitlinien-Register, Nr. 001/020

27 Leitlinie der Gesellschaft für Neonatologie und Pädiatische Intensivmedizin. Sepsis bei Kindern jenseits der Neonatalperiode. AWMF-Leitlinien-Register, Nr. 024/025

28 Harbarth S, Sudre P, Dharan S, Cadenas M, Pittet D. Outbreak of Enterobactercloacae related to understaffing, overcrowding, and poor hygiene practices. Infect Control Hosp Epidemiol 1999; 20(09):598-603 
29 Kluge S, Markewitz A, Jorch G, Putensen C, Quintel M, Sybrecht G. ed DIVI Jahrbuch 2016/2017. Medizinische Wissenschaftliche Verlagsgesellschaft 2016. Supportive Sepsistherapie

30 Brower RG, Lanken PN, MacIntyre N, et al; National Heart, Lung, and Blood Institute ARDS Clinical Trials Network. Higher versus lower positive end-expiratory pressures in patients with the acute respiratory distress syndrome. N Engl J Med 2004;351(04):327-336

31 Herting E, Hansen G. Monatsschr Kinderheilkd 2014;162:385. Doi:10.1007/s00112-013-2967-7

32 Ohlsson A, Lacy J. Intravenous immunoglobulin for suspected or subsequently proven infection in neonates. Cochrane Database Syst Rev 2010;(03):CD001239. Doi: 10.1002/14651858.CD001239.pub3

33 Sherenian M, Profit J, Schmidt B, et al. Nurse-to-patient ratios and neonatal outcomes: a brief systematic review. Neonatology 2013; 104(03):179-183
34 Tragende Gründe zum Beschlussentwurf des Gemeinsamen Bundesausschusses über eine Änderung der Qualitätssicherungsrichtliche Früh- und Reifgeborene: Änderung der Anlagen 2 und 3. 2015. Availabel at: https://www.g-ba.de/downloads/ 40-268-3391/2015-09-17_QFR-RL_Aenderung-Anlagen2-3_TrG. pdf. Accessed November 02, 2016

35 Cross CP, Liao S, Urdang ZD, Srikanth P, Garinis AC, Steyger PS. Effect of sepsis and systemic inflammatory response syndrome on neonatal hearing screening outcomes following gentamicin exposure. Int J Pediatr Otorhinolaryngol 2015;79(11):1915-1919

36 Stoll BJ, Hansen NI, Adams-Chapman I, et al; National Institute of Child Health and Human Development Neonatal Research Network. Neurodevelopmental and growth impairment among extremely low-birth-weight infants with neonatal infection. JAMA 2004;292(19):2357-2365 